\title{
The elusive and ungrateful lymphatic circulation may be a key determinant of Fontan failure
}

\author{
Yves d'Udekem, MD, PhD, FRACS, ${ }^{\text {a,b,c }}$ and Marc de Leval, MD, FRCS ${ }^{\mathrm{d}}$
}

\footnotetext{
From the a Department of Cardiac Surgery, Royal Children's Hospital, Melbourne, Victoria, Australia; ${ }^{b}$ Murdoch Childrens Research Institute, Melbourne, Victoria, Australia; ${ }^{c}$ Department of Pediatrics of the University of Melbourne, Melbourne, Victoria, Australia; and ${ }^{\mathrm{d} D e p a r t m e n t ~ o f ~ C a r d i o t h o r a c i c ~ S u r g e r y, ~ G r e a t ~ O r m o n d ~ S t r e e t ~}$ Hospital, London, United Kingdom.

The Victorian Government's Operational Infrastructure Support Program supported this research project.

Disclosures: Y.d'U. is a consultant for MSD and Actelion, and a National Health and Medical Research Council Clinical Practitioner Fellow (1082186). M.d.L. has nothing to disclose with regard to commercial support. Received for publication Jan 8, 2018; accepted for publication Jan 12, 2018; available ahead of print Feb 15, 2018. Address for reprints: Yves d'Udekem, MD, PhD, FRACS, Department of Cardiac Surgery, Royal Children's Hospital, Flemington Rd, Parkville, Melbourne, Victoria 3052, Australia (E-mail: yves.dudekem@rch.org.au). J Thorac Cardiovasc Surg 2018;155:2067-8 $0022-5223 / \$ 36.00$

Copyright $(2018$ by The American Association for Thoracic Surgery https://doi.org/10.1016/j.jtcvs.2018.01.026
}

The study of the lymphatic circulation has been inadequate because of its small size. Up to recently, we only knew from animal studies that lymphatics were organized in structural units, lymphangions, each comprising a valve and surrounded by smooth muscle cells and that these units could generate surprisingly high pressures. ${ }^{1}$ In the last decade, our insights have been boosted by the team of Aarhus by a line of experiments on human thoracic duct and peripheral lymphatics harvested during esophageal cancer and bariatric stomach surgery. ${ }^{2-5}$ They unveiled the pre- and afterload dependence of this circulation, their multiple biochemical interactions, and their innervations. Over the same period, the team of Philadelphia has developed imaging of the lymphatic circulation and has started to intervene with great success on these vessels. ${ }^{6}$ We are now realizing the possible role that the lymphatic circulation can play in the failure of the Fontan circulation. ${ }^{7}$ The question arises now whether some patients have a lymphatic circulation that cannot tolerate a Fontan circulation for innate or acquired reasons.

In that perspective, the work of the team of Toronto is welcome. ${ }^{8}$ In the analysis of 13 years of experience in 324 patients, they confirmed that developing a chylothorax at the time of the Fontan was associated with worse outcomes. They hypothesize that their lymphatic circulation was not suitable to accept a Fontan circulation. This is an important argument to further explore the lymphatic circulation before Fontan completion because some may be found to be poor candidates or require additional intervention before the Fontan. Identifying those with a chylothorax early after the operation may be beneficial because they might benefit from different management strategies.

The mechanisms of late Fontan failure are poorly understood, and the clinical presentations vary. Would it be possible that the failure of the lymphatic circulation to carry

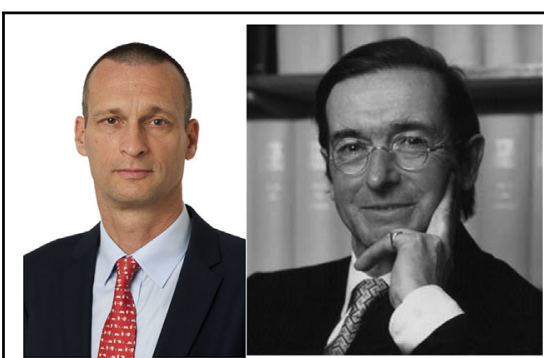

Yves d'Udekem, MD, PhD, FRACS, and Marc de Leval, MD, FRCS

Central Message

Patients developing chylothorax at the time of Fontan completion may have an inadequate lymphatic circulation for innate or acquired reasons.

See Article page 2069.

the extra load imposed by the Fontan circulation explain some of the observed clinical deteriorations? The lymphatic circulation can generate high pressures, but can it generate these pressures for decades?

We still have a long way to go before we solve these questions. Even the definition of "chylothorax" has remained mainly empirical, and it is difficult to know whether our set thresholds correspond accurately to any pathologic phenomenon. It is likely that the generation of lymphatic flow in the Fontan circulation is dependent on still unclear parameters. It has recently been demonstrated that liver fibrosis is present in patients with single ventricle physiology before Fontan completion. ${ }^{9}$ It would be surprising that the presence of hepatic interstitial fibrosis would not influence the generation of lymph and lead to some of the differences observed. Initially seen as a passive tube with function limited to absorption of nutrients, the intestine is now considered a complex organ, hosting a microbiome influencing multiple facets of health and disease. ${ }^{10}$

The work of the team of Toronto should motivate us to further expand our studies of the lymphatic circulation.

\section{References}

1. Kampmeier OF. Evolution and Comparative Morphology of the Lymphatic System. Springfield, IL: Charles C Thomas Publisher; 1969.

2. Telinius N, Drewsen N, Pilegaard H, Kold-Petersen $H$, de Leval M, Aalkjaer $\mathrm{C}$, et al. Human thoracic duct in vitro: diameter-tension properties, 
spontaneous and evoked contractile activity. Am J Physiol Heart Circ Physiol. 2010;299:H811-8.

3. Telinius N, Mohanakumar S, Majgaard J, Kim S, Pilegaard H, Pahle E, et al. Human lymphatic vessel contractile activity is inhibited in vitro but not in vivo by the calcium channel blocker nifedipine. J Physiol (Lond). 2014; 592:4697-714.

4. Telinius N, Baandrup U, Rumessen J, Pilegaard H, Hjortdal V, Aalkjaer $\mathrm{C}$, et al. The human thoracic duct is functionally innervated by adrenergic nerves. Am J Physiol Heart Circ Physiol. 2014;306: H206-13.

5. Telinius N, Majgaard J, Mohanakumar S, Pahle E, Nielsen J, Hjortdal V, et al. Spontaneous and evoked contractility of human intestinal lymphatic vessels. Lymphat Res Biol. 2017;15:17-22.
6. Dori Y, Keller MS, Fogel MA, Rome JJ, Whitehead KK, Harris MA, et al. MRI of lymphatic abnormalities after functional single-ventricle palliation surgery. AJR Am J Roentgenol. 2014;203:426-31.

7. Rychik J. The relentless effects of the Fontan paradox. Semin Thorac Cardiovasc Surg. 2016;19:37-43.

8. Lo Rito M, Al-Radi OO, Saedi A, Kotani Y, Sivarajan VB, Russel J, et al. Chylothorax and pleural effusion in contemporary extracardiac fenestrated Fontan completion. J Thorac Cardiovasc Surg. 2018;155:2069-77.

9. Schwartz MC, Sullivan L, Cohen MS, Russo P, John AS, Guo R, et al. Hepatic pathology may develop before the Fontan operation in children with functional single ventricle: an autopsy study. J Thorac Cardiovasc Surg. 2012;143:904-9.

10. Lynch SV, Pedersen O. The human intestinal microbiome in health and disease. $N$ Engl J Med. 2016;375:2369-79. 